\title{
Melanoma oral amelanótico metastático com acometimento neurológico e gonadal em um cão fêmea - relato de caso
}

[Metastatic oral amelanotic melanoma with neurologic and gonadal involvement in a female dog - case report]

\author{
C.E.B. Lopes $^{1}$, M.V.L. Moreira ${ }^{2}$, B.A. Carvalho ${ }^{2}$, P.H. Carvalho ${ }^{3}$, \\ E. Ferreira ${ }^{3}$, R.M.C. Guedes ${ }^{3}$, R. Ecco $^{3 *}$
}

${ }^{1}$ Residente - Escola de Veterinária - Universidade Federal de Minas Gerais - Belo Horizonte, MG ${ }^{2}$ Aluno de pós-graduação - Escola de Veterinária - Universidade Federal de Minas Gerais - Belo Horizonte, MG ${ }^{3}$ Escola de Veterinária - Universidade Federal de Minas Gerais - Belo Horizonte, MG

\section{RESUMO}

Relata-se um caso de melanoma oral disseminado em uma cadela de dois anos, com protrusão de bulbo ocular unilateral e quadro convulsivo progressivo. Os exames de imagem revelaram aumento de volume nas regiões submandibular, maxilar e cerebral, padrão nodular pulmonar e aumento das dimensões ovarianas. A citologia da massa submandibular indicou proliferação epitelial maligna, enquanto a biópsia excisional foi sugestiva de melanoma amelanótico. $\mathrm{Na}$ necropsia, havia uma massa gengival localmente infiltrativa e nodulações brancas nos linfonodos, nos rins, no pulmão, no cérebro e nos ovários, indicativas de metástase. O diagnóstico histopatológico consistiu de neoplasia maligna metastática indiferenciada, indicativo de melanoma amelanótico. Células caracterizadas por núcleo com cromatina espessa, múltiplos nucléolos bem evidentes, mitoses atípicas e multinucleações consistiram nos principais critérios de malignidade. No espaço peritrabecular ósseo facial, havia rara diferenciação pigmentar melanocítica, confirmada histoquimicamente pela técnica de Fontana-Massom e Giemsa. Algumas células foram positivas pela imunohistoquímica para PNL-2 e Melan-A, e o diagnóstico de melanoma amelanótico disseminado foi firmado. A indiferenciação neoplásica marcante, com disseminação metastática multissistêmica e acometimento mútuo de sítios anatômicos pouco comuns, conjuntamente com a ampla variação dos padrões celulares, foi responsável pelo desafio diagnóstico do presente caso, ressaltando o papel decisivo da imuno-histoquímica para confirmação diagnóstica. A importância clínica deste trabalho consiste ainda em alertar a comunidade clínica e científica acerca da dificuldade diagnóstica, devendo-se considerar o melanoma amelanótico como diferencial mesmo em casos de lesões orais menos perceptíveis e/ou desprovidas de pigmentação.

Palavras-chave: cão, neoplasia, amelanótico, metástase, ovário

\begin{abstract}
A case of disseminated oral melanoma in a two year old female dog with unilateral protuberance of the eye bulb and progressive seizure is described. Imaging exams revealed increase of the submandibular, maxillary and cerebral regions, nodular pattern in lungs and increased ovarian dimensions. The cytology of the submandibular mass indicated a malignant epithelial proliferation, whereas the excisional biopsy indicated an amelanotic melanoma. At necropsy, a locally infiltrating gingival mass and white nodules in the lymph nodes, kidneys, lung, brain and ovaries were observed, indicative of metastases. Histopathological diagnosis consisted of an undifferentiated malignant metastatic neoplasm. Nucleus with coarse chromatin, prominent nucleoli, bizarre mitotic figures and multinucleated cells were the major malignant features. There was a poor melanocytic pigment differentiation in the peritrabecular space of facial bones, confirmed by Fontana-Masson and Giemsa histochemical techniques. Only a few cells were immunohistochemically positive for PNL-2 and Melan-A and the diagnosis of a disseminated amelanotic melanoma was performed. The diagnostic challenge was based on marked neoplastic undifferentiation, with multisystemic metastasis and mutual involvement of uncommon anatomic sites, associated with a large variability of cellular patterns, highlighting the decisive role of immunohistochemistry for diagnostic confirmation. Therefore, the clinical importance of this study is to warn the clinical and scientific community about the diagnostic challenge, considering the amelanotic melanoma as a differential even in cases of poorly apparent and/or nonpigmented oral lesions.
\end{abstract}

Keywords: dog, neoplasm, amelanotic, metastasis, ovary

Recebido em 4 de fevereiro de 2020

Aceito em 28 de julho de 2020

*Autor para correspondência (corresponding author)

E-mail: eccoro.ufmg@gmail.com 


\section{INTRODUÇÃO}

O melanoma é uma neoplasia maligna de origem melanocítica derivada do folheto neuroectodérmico (Goldschmidt e Goldschmidt, 2017). Diferentemente de sua contraparte benigna, o melanoma possui alto potencial metastático, com prognóstico invariavelmente reservado (Pippi e Gomes, 2016; Goldschmidt e Goldschmidt, 2017). A neoplasia origina-se frequentemente na pele e em regiões pigmentadas e, apesar da nomenclatura, o melanoma pode se apresentar completamente despigmentado, sendo considerado, nesse caso, melanoma amelanótico (Uzal et al., 2016).

As neoplasias orais contabilizam 5\% de todos os neoplasmas em pequenos animais, sendo o melanoma a neoplasia oral mais comum em cães. Dessas, apenas um terço é representado pelo melanoma amelanótico (Pippi e Gomes, 2016). Não há predisposição sexual para a ocorrência da neoplasia. No entanto, há uma maior propensão para seu surgimento em animais da raça Golden Retriever, sendo 12 anos a idade média descrita como a de maior incidência da neoplasia maligna (Munday et al., 2017).

A ocorrência de metástases à distância é relativamente comum em casos de melanoma oral. No entanto, a disseminação da neoplasia com envolvimento ovariano e cerebral concomitante não foi ainda documentada. Portanto, descreve-se um caso atípico de melanoma oral disseminado em um cão fêmea de dois anos de idade, para destacar à comunidade científica os desafios no diagnóstico dessa condição.

\section{CASUÍSTICA}

Um cão fêmea da raça Golden Retriever, de dois anos de idade, regularmente vacinada e domiciliada, foi encaminhada ao serviço de cirurgia de pequenos animais do Hospital Veterinário, com queixa prévia de alteração conformacional no olho direito. Durante a avaliação pré-cirúrgica, foi identificada assimetria de face com protrusão do bulbo ocular direito, blefaroespasmo e hiperemia conjuntival (dia zero). Foi solicitada tomografia computadorizada (TC), radiografia torácica e ultrassonografia abdominal investigativa, realizadas nove dias após o atendimento clínico inicial. A TC revelou aumento de volume na região retrobulbar, além de massa no lobo temporal do hemisfério cerebral direito e massa na região submandibular direita (Fig. 1A, 1B). O exame radiográfico sugeriu padrão nodular pulmonar (Fig. 1C), enquanto o exame ultrassonográfico indicou aumento acentuado das dimensões ovarianas e das cavidades císticas (Fig. 1D).

A citologia aspirativa por agulha fina da massa submandibular, realizada no $14^{\circ}$ dia após a primeira consulta, sugeriu processo proliferativo epitelial, possivelmente maligno. A biópsia excisional da massa submandibular foi procedida no $28^{\circ}$ dia da abordagem clínica inicial. A amostra foi fixada em solução de formalina a $10 \%$, tamponada e neutra, sendo submetida ao processamento histológico rotineiro, com coloração pela hematoxilina e eosina (HE) (Luna, 1968). Microscopicamente, foi possível confirmar o sítio de acometimento (linfonodo submandibular), com diagnóstico histopatológico compatível com neoplasia maligna indiferenciada de provável origem melanocítica (melanoma amelanótico).

No pós-operatório tardio da excisão da massa submandibular (quinta semana do atendimento inicial), o animal desenvolveu apatia e dispneia progressiva, com poliúria, polidipsia e sialorreia intensa. O cão desenvolveu prostração e quadro neurológico de crises convulsivas agrupadas (cluster) na sexta semana. O proprietário declinou dos tratamentos recomendados, sendo, então, realizada a eutanásia do animal, o qual foi posteriormente encaminhado ao setor de Patologia Animal para exame anatomopatológico. Macroscopicamente, o bulbo ocular direito estava discretamente prolapsado, com hiperemia acentuada das conjuntivas palpebrais e bulbar. No assoalho do espaço retrobulbar direito, havia uma massa irregular, branco-amarelada, medindo $1,5 \mathrm{x}$ $1,5 \times 1,0 \mathrm{~cm}$.

$\mathrm{Na}$ gengiva, adjacente ao terceiro dente molar superior direito da cavidade oral, observou-se aumento de volume irregular, esbranquiçado, sólido e firme, medindo 2,0 x 1,0 x 1,0cm (Fig. 2A). Os linfonodos submandibulares estavam intensamente aumentados, firmes, com superfície irregular e contendo nódulos esbranquiçados que se aprofundavam no parênquima. À secção transversal do crânio, na altura do terceiro dente molar superior direito, notou-se assimetria acentuada dos ossos da face devido à invasão óssea difusa pela neoplasia oral no antímero 
direito dos ossos maxilar, palatino, zigomático, lacrimal e etmoturbinados (Fig. 2B). Na transição entre os lobos temporal e occipital do hemisfério cerebral direito, havia um tumor proeminente $\mathrm{e}$ infiltrativo, firmemente aderido às meninges, medindo $2,5 \mathrm{~cm}$ de diâmetro. A superfície de corte da massa era sólida, branca e firme, comprimindo o parênquima cerebral adjacente (Fig. 2C).
Nódulos tumorais variando de 0,5 a $2,0 \mathrm{~cm}$, similares ao descrito acima, foram visualizados no lobo pulmonar cranial esquerdo, no córtex de ambos os rins e no linfonodo renal esquerdo. Ambos os ovários estavam acentuadamente aumentados e com superfície irregular e esbranquiçada. Na superfície de corte, havia áreas sólidas e esbranquiçadas, com áreas cavitárias periféricas de centro necrótico (Fig. 2D).
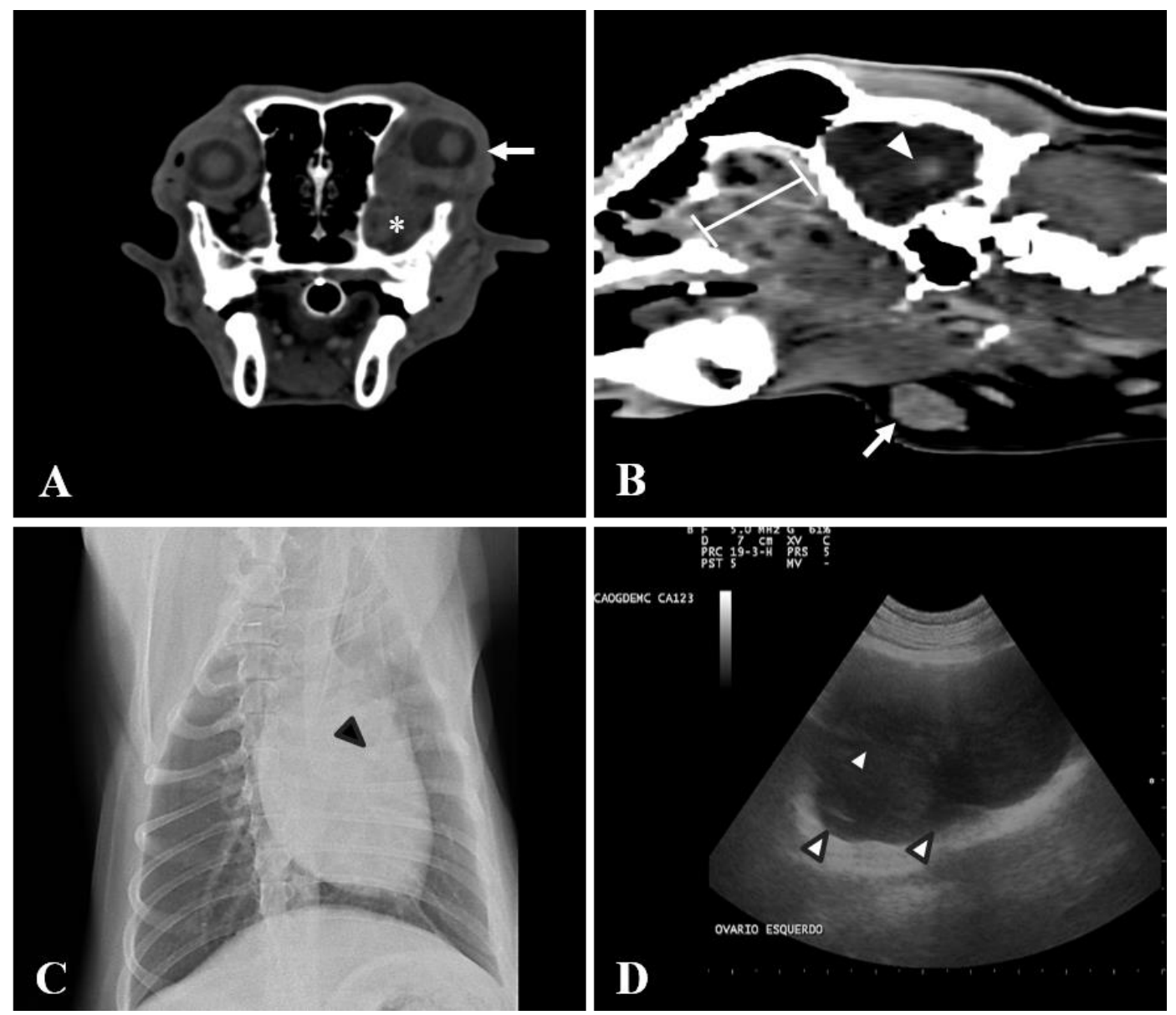

Figura 1. Exames de imagem do cão fêmea Golden Retriever, dois anos de idade. A. Tomografia computadorizada contrastada $(2,0 \mathrm{~mL} / \mathrm{kg} / \mathrm{IV}$ de ioexol) do crânio em plano transversal, janela de tecidos moles (angio). Massa isodensa, amorfa, com contornos irregulares, retrobulbar (asterisco), captação heterogênea de contraste, com deslocamento dorsolateral do bulbo ocular direito (seta), osteólise do osso frontal direito e invasão do recesso maxilar. B. Tomografia computadorizada contrastada $(2,0 \mathrm{~m} / \mathrm{kg} / \mathrm{IV} \mathrm{de}$ ioexol) do crânio em plano sagital do antímero direito. Massa retrobulbar no recesso maxilar (espaço entre barras), com captação heterogênea de contraste. Massa encefálica (cabeça de seta) de contornos regulares e definidos em topografia de lobos temporal e occipital direitos, com captação homogênea de contraste. Linfonodo mandibular direito (seta branca) com aumento de volume acentuado e captação heterogênea de contraste. C. Radiografia torácica em projeção ventrodorsal, com área nodular delimitada, com radiopacidade de tecido mole (cabeça de seta) no quarto espaço intercostal esquerdo. D. Ultrassonografia abdominal evidenciando aumento de volume do ovário esquerdo, com estruturas circunscritas de conteúdo anecoico (cabeças de seta). 

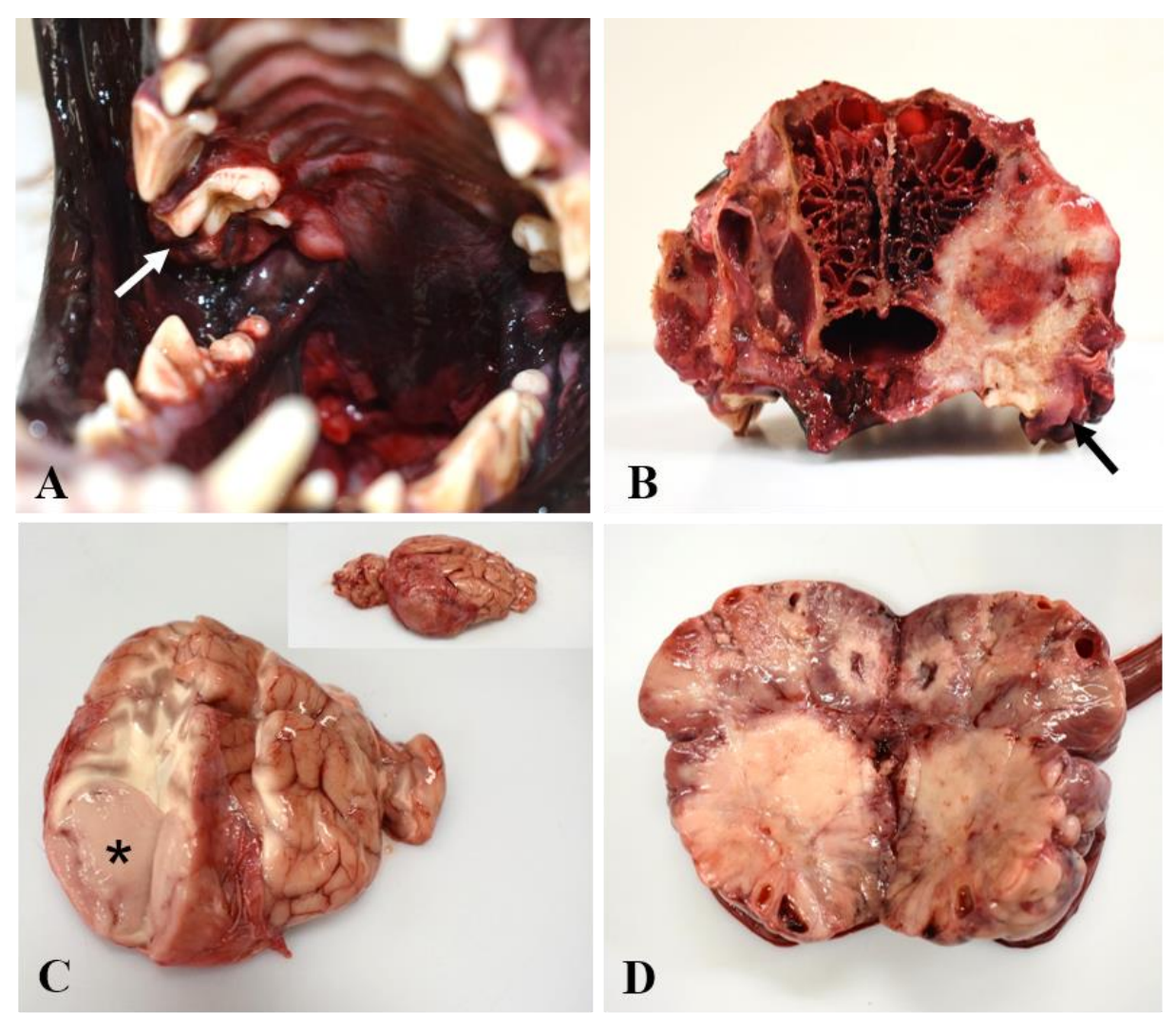

Figura 2. Achados anatomopatológicos do cão fêmea Golden Retriever, dois anos de idade. A. Cavidade oral. Lesão tumoral (seta) adjacente ao terceiro dente molar superior direito. B. Corte transversal do crânio. $\mathrm{Na}$ maxila direita, a massa tumoral branca envolve a gengiva ao redor do dente molar (seta) e invade os ossos da maxila e os seios paranasais direitos. C. Encéfalo com assimetria do hemisfério direito (detalhe) e, na imagem maior, visão da secção na transição temporo-occipital telencefálica. No parênquima, há um nódulo esbranquiçado e sólido (asterisco) firmemente aderido aos folhetos meníngeos (detalhe), com compressão e substituição das substâncias cinzenta e branca. D. Ovário esquerdo. Superfície de corte heterogênea, com nodulações tumorais sólidas ou com cavitações, as quais substituíram quase totalmente o parênquima.

Após fixação em solução de formalina a $10 \%$ neutra e tamponada, a secção óssea facial foi submetida ao protocolo de descalcificação por 15 dias, com ácido fórmico a $24 \%$, conforme Caputo et al. (2010), seguido do processamento histológico padrão (Luna, 1968). A histopatologia da massa oral consistiu de neoplasia não encapsulada, mal delimitada, infiltrativa, com células redondas isoladas, ou dispostas em arranjos epitelioides. O citoplasma dessas células era arredondado, eosinofílico e moderadamente amplo. O núcleo era paracentral de cromatina densa e os nucléolos eram bem evidentes. Havia pleomorfismo acentuado, com numerosas células multinucleadas, intensa anisocariose e elevada contagem mitótica (52 mitoses em 10 campos de maior aumento, 400x) (Fig. 3A).
Características histológicas semelhantes foram observadas nas neoformações do telencéfalo, no espaço retrobulbar direito, na maxila (Fig. 3B), nos ossos nasais, no pulmão, nos linfonodos renais e nos ovários. Nos ossos da face, a neoplasia infiltrava e comprimia os cornetos nasais, com invasão óssea e do nervo local (Fig. 3C). No espaço peritrabecular, havia rara diferenciação pigmentar, com acúmulo de grânulos acastanhados intracitoplasmáticos (Fig. 3D). Tais grânulos coraram em preto e em verdeescuro pelas colorações de Fontana-Masson e Giemsa, respectivamente (Luna, 1968). Não houve positividade na coloração pelo azul da prússia (Luna, 1968), indicando não se tratar de hemossiderina. 


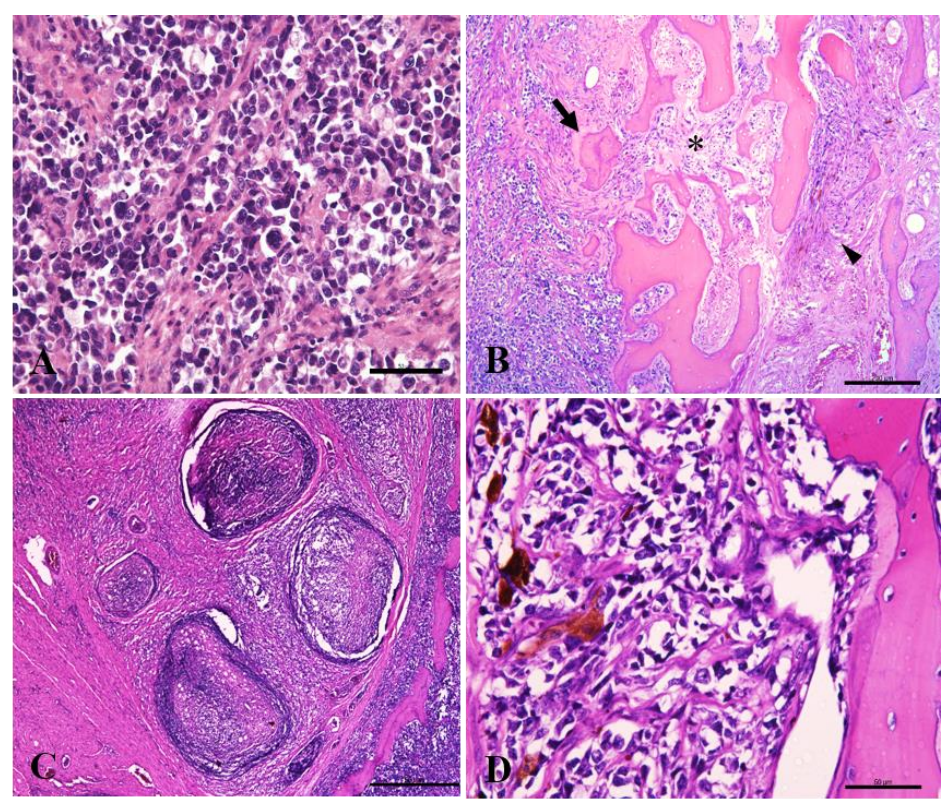

Figura 3. Histopatologia do melanoma no cão da Fig. 2. Hematoxilina e eosina. A. Mucosa oral. Células epitelioides anaplásicas com intenso pleomorfismo e multinucleações frequentes. Barra $=50 \mu \mathrm{m}$. B. Osso maxilar. Infiltração de células neoplásicas com descontinuidade de trabéculas ósseas (seta), mielofibrose (asterisco) e mieloptise (cabeça de seta). Barra $=200 \mu \mathrm{m}$. C. Osso maxilar. Ramos do nervo trigêmeo com os espaços endo- e perineural difusamente infiltrados pela neoplasia. Barra $=500 \mu \mathrm{m}$. D. Osso maxilar. Raras células neoplásicas com pigmento acastanhado intracitoplasmático. Barra $=50 \mu \mathrm{m}$.

Amostras da neoplasia oral e das metástases no osso maxilar, no encéfalo e no ovário foram submetidas à imuno-histoquímica, com anticorpos monoclonais para antígenos melanocíticos (Smedley et al., 2011). Os anticorpos utilizados consistiram de anti-Melan-A e anti-PNL-2 (Santa Cruz Biotechnology ${ }^{\circledR}$ ), na concentração de 1:100 e 1:50, respectivamente. A amplificação da reação foi realizada com o sistema comercial Novolink ${ }^{\circledR}$ (Novolink Polymer
Detection System; Leica Biosystems), de acordo com as instruções fornecidas pelo fabricante. A revelação da reação foi realizada com 3.3'diaminobenzidina (DAB), e as lâminas foram contracoradas por Giemsa. Vinte por cento das células neoplásicas das amostras da neoplasia oral e dos nódulos do encéfalo e ovário tiveram marcação fracamente positiva para Melan-A e PNL-2 (Fig. 4), enquanto a amostra do osso maxilar foi negativa para ambos os marcadores.

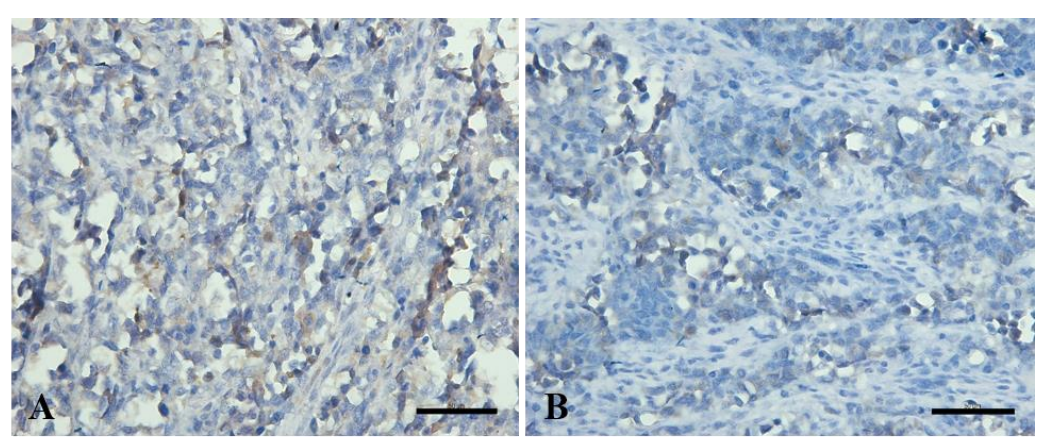

Figura 4. Imuno-histoquímica da neoplasia oral mostrada na Fig. 3. A. Células neoplásicas com fraca imunomarcação citoplasmática para Melan-A. Barra $=50 \mu \mathrm{m}$. B. Células neoplásicas com fraca imunomarcação citoplasmática para PNL-2. Barra $=50 \mu \mathrm{m}$. Revelação com DAB e contracoloração por Giemsa. 


\section{DISCUSSÃO}

Os achados macroscópicos, histopatológicos, histoquímicos e imuno-histoquímicos possibilitaram o diagnóstico de melanoma amelanótico oral, com múltiplas metástases no cão do presente relato. $\mathrm{O}$ padrão de acometimento neoplásico sugere que a via hematógena e a linfática estiveram presentes, com agressividade também local, justificada pela invasão óssea direta. O acometimento das estruturas cranioencefálicas se deu majoritariamente na porção direita do crânio, em razão da localização da lesão primária.

Apesar da lateralidade da lesão no hemisfério direito telencefálico, é possível que a rota metastática da neoplasia para o encéfalo tenha decorrido da chegada de êmbolos metastáticos nos vasos meníngeos por via hematógena, visto que não havia ligação direta entre a massa encefálica e a retrobulbar. Acredita-se que a ocorrência da lesão cranioencefálica justifica a apresentação clínica descrita, ainda que os sinais clínicos convulsivos tenham sido vagos e pouco específicos.

O comportamento agressivo da neoplasia quanto à infiltração óssea e à metástase para sítios distantes pouco usuais diferiu do comumente relatado na literatura, sobretudo ao se considerar a idade jovem do animal (Rolim et al., 2012; Grüntzig et al., 2015). É possível, portanto, que a localização da neoplasia primária e sua elevada contagem mitótica tenham contribuído para a progressão rápida (Smedley et al., 2011). A gengiva é o sítio oral mais comumente acometido em cães; no entanto, o tempo de sobrevida do animal parece não depender da localização tumoral e do índice mitótico (Ramos-Vara et al., 2000).

Metástases de melanoma amelanótico podem ter células pigmentadas (Munday et al., 2017), as quais foram evidenciadas apenas microscopicamente na região do osso facial, no presente caso. O desafio diagnóstico deste caso consistiu, principalmente, na marcante indiferenciação da lesão primária oral. Grossi et al. (2015) ressaltaram a importância em diferenciar melanócitos de melanófagos teciduais. A avaliação histológica dos critérios de malignidade e a íntima relação com as demais células neoplásicas indiferenciadas foram importantes para discernir as células melanocíticas pigmentadas de melanócitos típicos ectópicos.

Tal confirmação foi possível por marcação imuno-histoquímica para Melan-A e PNL-2, mesmo na ausência de imunomarcação por muitas células neoplásicas, supostamente devido à indiferenciação intensa. Com relação às amostras descalcificadas, é possível que o processo de descalcificação dos ossos da face tenha interferido com a sensibilidade, podendo justificar a negatividade para ambos os marcadores na metástase no osso maxilar. Diferentemente da descalcificação por ácido clorídrico, Ramos-Vara e Miller (2011) afirmaram que o processamento pelo ácido fórmico não interfere na imunorreatividade dos anticorpos anti-Melan-A, anti-PNL-2 e anti-tirosinase, os quais foram utilizados no presente caso. No entanto, os autores afirmam que houve perda discreta de sensibilidade do anticorpo PNL-2 em uma amostra descalcificada pelo tempo máximo utilizado no estudo (sete dias). Esse tempo foi oito dias inferior ao utilizado no presente trabalho (15 dias).

Acerca do exame citopatológico prévio, é possível que este tenha sido amparado na visualização de arranjos epitelioides malignos, juntamente com a completa ausência de pigmentação, favorecendo a conclusão de origem carcinomatosa. Essa alteração celular conformacional (padrão epitelioide) costuma variar segundo o grau de atipia de alguns melanomas, sendo ainda possível a observação do padrão fusiforme ou de células mistas, o que justifica a dificuldade diagnóstica por citopatologia (Smith et al., 2002; Smedley et al., 2011).

Não obstante, um estudo recente de correlação cito-histopatológica de melanomas orais em cães demonstrou uma baixa correlação entre as técnicas (Grimes et al., 2017). Nessa linha, os principais diferenciais de neoplasias malignas da cavidade oral consistem no fibrossarcoma, no condrossarcoma, no carcinoma de células escamosas e no osteossarcoma. No entanto, as neoplasias do epitélio odontogênico e do ligamento periodontal também devem ser incluídas na lista de diagnósticos diferenciais (Pippi e Gomes, 2016). 
Pelo conhecimento dos autores, não há descrição prévia de melanoma oral com metástase ovariana em cadelas. Em mulheres, metástases ovarianas são pouco descritas, sendo geralmente tardias (Mendel et al., 2017). Contudo, há relatos de melanoma primário ovariano, geralmente associado à ocorrência de teratoma, o que representa um desafio diagnóstico na ausência de um sítio neoplásico extragonadal (Paola et al., 2018). Tal hipótese foi desconsiderada no presente relato, com base na epidemiologia para a espécie, nas características histológicas e na neoplasia oral primária com metástases em órgãos próximos. Nesse âmbito, ressalta-se a importância dos estudos em cães e defende-se sua utilização como modelos para estudo em seres humanos quanto às características clínicas, histopatológicas e genéticas das neoplasias melanocíticas nesses animais.

\section{CONCLUSÕES}

A marcante indiferenciação das células neoplásicas e as múltiplas metástases, incluindo sítios anatômicos pouco descritos, em conjunto com a ampla variação dos padrões celulares, foram responsáveis pelo desafio diagnóstico do presente caso. Ressalta-se ainda a imunohistoquímica como fundamental para a confirmação diagnóstica. Enfatiza-se também a importância da investigação semiológica minuciosa, com o exame detalhado da cavidade oral em casos de suspeita de acometimento das estruturas cranioencefálicas, não subestimando as lesões orais menos perceptíveis e/ou desprovidas de pigmentação, sempre considerando o melanoma como diagnóstico diferencial.

\section{REFERÊNCIAS}

CAPUTO, L.F.G.; GITIRANA, L.B.; MANSO, P.P.A. Técnicas histológicas. In: MOLINARO, E.M.; CAPUTO, L.F.G.; AMENDOEIRA, M.R.R. Conceitos e métodos para formação de profissionais em laboratórios de saúde. Rio de Janeiro: EPSJV, IOC, 2010. v.2, p.89-188.

GOLDSCHMIDT, M.H.; GOLDSCHMIDT, K.H. Epithelial and melanocytic tumors of the skin. In: MEUTEN, D.J. Tumors in domestic animals. 5.ed. Ames: Iowa State, 2017. p.88-141.
GRIMES, J.A.; MATZ, B.M.; CHRISTOPHERSON, P.W. et al. Agreement between cytology and histopathology for regional lymph node metastasis in dogs with melanocytic neoplasms. Vet. Pathol., v.54, p.579-587, 2017.

GROSSI, A.B.; HYTTEL, P.; JENSEN, H.E. et al. Porcine melanotic cutaneous lesions and lymph nodes: immunohistochemical differentiation of melanocytes and melanophages. Vet. Pathol., v.52, p.83-91, 2015.

GRÜNTZIG, K.; GRAF, R.; HASSIG, M. et al. The Swiss canine cancer registry: a retrospective study on the occurrence of tumours in dogs in Switzerland from 1955 to 2008. J. Comp. Pathol., v.152, p.161-171, 2015.

LUNA, L.G. Manual of histologic staining methods of the Armed Forces Institute of Pathology. 3.ed. New York: McGraw-Hill, 1968. 258p.

MENDEL, A.; TERZIBACHIAN, J.J.; AUBIN, F. et al. Ovarian metastasis of a malignant melanoma: a case report. J. Gynecol. Obstet. Hum. Reprod., v.46, p.461-462, 2017.

MUNDAY, J.S.; LÖHR, C.V.; KIUPEL, M. Tumors of the alimentary tract. In: MEUTEN, D.J. Tumors in domestic animals. 5.ed. Ames: Iowa State, 2017. p.499-601.

PAOLA, A.; MARIA, R.S.; LAURA, C. et al. A rare melanoma feature with primary ovarian origin: a case report and the literature review. Obstet. Gynecol. Sci., v.61, p.282-285, 2018.

PIPPI, N.L.; GOMES, C. Neoplasias da cavidade oral. In: DALECK, C.R.; DE NARDI, A.B. Oncologia em cães e gatos. 2.ed. Rio de Janeiro: Roca, 2016. cap.28, p.385-394.

RAMOS-VARA, J.A.; BEISSENHERZ, M.E.; MILLER, M.A. et al. Retrospective study of 338 canine oral melanomas with clinical, histologic, and immunohistochemical review of 129 cases. Vet. Pathol., v.37, p.597-608, 2000.

RAMOS-VARA, J.A.; MILLER, M.A. Immunohistochemical identification of canine melanocytic neoplasms with antibodies to melanocytic antigen PNL2 and tyrosinase: comparison with Melan a. Vet. Pathol., v.48, p.443-450, 2011. 
ROLIM, V.M.; CASAGRANDE, R.A.; WATANABE, T.T. et al. Melanoma amelanótico em cães: estudo retrospectivo de 35 casos (20042010) e caracterização imuno-histoquímica. Pesq. Vet. Bras., v.32, p.340-346, 2012.

SMEDLEY, R.C.; SPANGLER, D.G.; ESPLIN, B.E. et al. Prognostic markers for canine melanocytic neoplasms: a comparative review of the literature and goals for future investigation. Vet. Pathol., v.48, p.54-72, 2011.
SMITH, S.H.; GOLDSCHMIDT, M.H.; MCMANUS, P.M.A comparative review of melanocytic neoplasms. Vet. Pathol., v.39, p.651678, 2002.

UZAL, F.A.; PLATTNER, B.L.; HOSTETTER, J.M. Alimentary system. In: MAXIE, M.G. Jubb, Kennedy, and Palmer's pathology of domestic animals. 6.ed. Philadelphia: Elsevier Saunders, 2016. p.1-257. 